УДК 665.7.038.3

АНАЛИЗ КАЧЕСТВА БЕНЗИНОВ ВТОРИЧНЫХ ПРОЦЕССОВ

С ПОМОЩЬЮ ИНФРАКРАСНОГО СПЕКТРА

ПРИ ДОБАВЛЕНИИ КИСЛОРОДСОДЕРЖАЩИХ СОЕДИНЕНИЙ

\title{
QUALITY ANALYSIS OF SECONDARY PROCESSES PETROLES USING THE INFRARED SPECTRUM BY ADDING OXYGEN CONTAINING COMPOUNDS
}

А.Т. Гильмутдинов, И.Г. Лапшин, И.Р. Тафтиева, Э.Р. Шавалиева

Уфимский государственный нефтяной технический университет г. Уфа, Российская Федерация

Amir T. Gilmutdinov, Igor G. Lapshin, Irina R. Taftieva, Elvira R. Shavalieva

Ufa State Petroleum Technological University, Ufa, Russian Federation e-mail: ammir59@mail.ru

Аннотация. В статье рассмотрены наиболее перспективные оксигенаты, применяемые в моторных топливах для улучшения энергетических и экологических показателей, а также определено влияние добавок на показатели качества товарного топлива. Содержание данных соединений определяется такими требованиями, как ограничение объемной доли ароматических углеводородов, октановое число, обязательное наличие оксигенатов в пересчете на кислород. Подобраны кислородсодержащие соединения на предмет их возможного применения как антидетонационных добавок к топливам.

Широкое распространение оксигенаты получили благодаря высоким октановым числам смешения и улучшенным экологическим свойствам по сравнению с аналогами. В настоящее время применяются октаноповышающие 
добавки, такие как алкилат, метил-трет-бутиловый эфир, этил-трет-бутиловый эфир, метанол, этанол, трет-бутанол, изопропиловый спирт. Большее применение среди оксигенатов имеет метил-трет-бутиловый эфир, он позволяет получать товарные бензины с высокой детонационной стойкостью и стабильностью, с уменьшенным нагарообразованием, пониженной токсичностью. Самый востребованный среди спиртов - метанол, который смешивается с бензином в любом соотношении и образует минимум нагара, а продукты его сгорания менее токсичны по сравнению с бензинами. Предлагается метод для определения содержания оксигенатов, а именно инфракрасная спектрометрия. Идентификация соединений по спектральным данным основана на поглощении веществом в области излучения, которое осуществляется за счет колебаний атомов в молекулах. Перемещение между колебательными состояниями имеют форму спектра, где каждому колебанию соответствует определенная длина волны. Получены спектрограммы изомеризата, алкилата, риформата, бензина каталитического крекинга, бензина коксования, бензина АИ-95, совмещенные спектры трет-бутанола, метил-третбутилового эфира и метанола.

Abstract. The article discusses the most promising oxygenates used in motor fuels to improve energy and environmental performance, the effect of additives on quality indicators of commercial fuel. The content of these compounds is determined by such requirements as limiting the volume fraction of aromatic hydrocarbons, octane number, and the obligatory presence of oxygenates in terms of oxygen. Oxygen-containing compounds were selected for their possible use as antiknock additives to fuels.

Oxygenates are widely used due to their high octane mixing numbers and improved environmental properties compared to their analogues. Octane enhancing additives such as alkylate, methyl tert-butyl ether, ethyl tert-butyl ether, methanol, ethanol, tert-butanol, isopropyl alcohol are currently used. Methyl tert-butyl ether has a greater use among oxygenates; it allows one to produce commercial petrols with high detonation resistance and stability, with 
reduced carbonization, and reduced toxicity. The most popular among alcohols is methanol, which is mixed with gasoline in any ratio and forms a minimum of soot, and its combustion products are less toxic compared to petroles. A method is proposed for determining the oxygenate content, namely infrared spectrometry. Identification of compounds by spectral data is based on absorption by a substance in the field of radiation, which carried out due to oscillations of atoms in molecules. The displacement between the vibrational states is in the form of a spectrum, where each oscillation corresponds to a certain wavelength. Spectrograms of isomerizate, alkylate, reformate, catalytic cracking gasoline, coking gasoline, AI-95 gasoline, combined spectra of tertbutanol, methyl tert-butyl ether and methanol were obtained.

Ключевые слова: инфракрасная спектроскопия; бензин; оксигенаты; метил-трет-бутиловый эфир; трет-бутанол; алкилат; октановое число

Key words: infrared spectroscopy; petrol; oxygenates; methyl tert-butyl ether; tert-butanol; alkylate; octane number

Транспортный рынок постоянно наращивает объёмы производства бензинов, что ведет к загрязнению окружающей среды. С каждым годом экологические требования к автомобильным бензинам ужесточаются, это обуславливает необходимость применения в их составе добавок, в частности кислородсодержащих соединений. Они позволяют повысить эксплуатационные характеристики, при этом не ухудшая экологических требований.

Долгое время в качестве октаноповышающей добавки применялся тетраэтилсвинец ввиду своей относительной дешевизны и эффективности. В чистом виде вещество не использовалось, а применялось в виде этиловой жидкости в качестве антидетонатора. Соединение представляет собой летучую ядовитую жидкость. Тетраэтилсвинец проникает в организм через верхние дыхательные пути, поражает нервную систему, вызывая острые и 
хронические отравления. Из-за своей токсичности его применение было запрещено в 1972 году в Америке и в 2003 году в России.

Современные международные стандарты на автомобильные бензины требуют обязательного наличия в их составе 2,7 \% масс. оксигенатов в пересчете на чистый кислород [1]. При этом увеличивается полнота сгорания топлива, уменьшается содержание оксида углерода и углеводородов в выхлопных газах двигателя.

Физико-химические свойства октаноповышающих соединений представлены в таблице 1.

Таблица 1. Физико-химические свойства оксигенатов и базового бензина

\begin{tabular}{|l|c|c|c|c|c|c|c|}
\hline Показатель & Метанол & Этанол & $\begin{array}{c}\text { Изопропи- } \\
\text { ловый } \\
\text { спирт }\end{array}$ & МТБЭ & ЭТБЭ & $\begin{array}{c}\text { Трет- } \\
\text { бутанол }\end{array}$ & $\begin{array}{c}\text { Базовый } \\
\text { бензин }\end{array}$ \\
\hline $\begin{array}{l}\text { Температура } \\
\text { кипения, }{ }^{\circ} \mathrm{C}\end{array}$ & 64,5 & 78,4 & 82,4 & 55,2 & 72,8 & 83,0 & $35-180$ \\
\hline $\begin{array}{l}\text { ОЧИМ/ } \\
\text { ОЧММ }\end{array}$ & $\begin{array}{c}111 / \\
94\end{array}$ & $\begin{array}{c}108 / \\
92\end{array}$ & $\begin{array}{c}97 / \\
86\end{array}$ & $\begin{array}{c}110 / \\
102\end{array}$ & $\begin{array}{c}118 / \\
105\end{array}$ & $\begin{array}{c}106 / \\
95\end{array}$ & $\begin{array}{c}85-98 / \\
72-85\end{array}$ \\
\hline $\begin{array}{l}\text { Теплота } \\
\text { сгорания, } \\
\text { МДж/кг }\end{array}$ & 22,3 & 26,9 & 33,3 & 38,2 & 23,5 & 28,1 & 42,5 \\
\hline $\begin{array}{l}\text { Объемная доля } \\
\text { оксигенатов, } \\
\text { \%, не более }\end{array}$ & 1,0 & 5,0 & 10,0 & 15,0 & 15,0 & 7,0 & - \\
\hline
\end{tabular}

Зависимость теплоты сгорания оксигенатов от октанового числа по моторному методу (ОЧММ) представлена на рисунке 1.

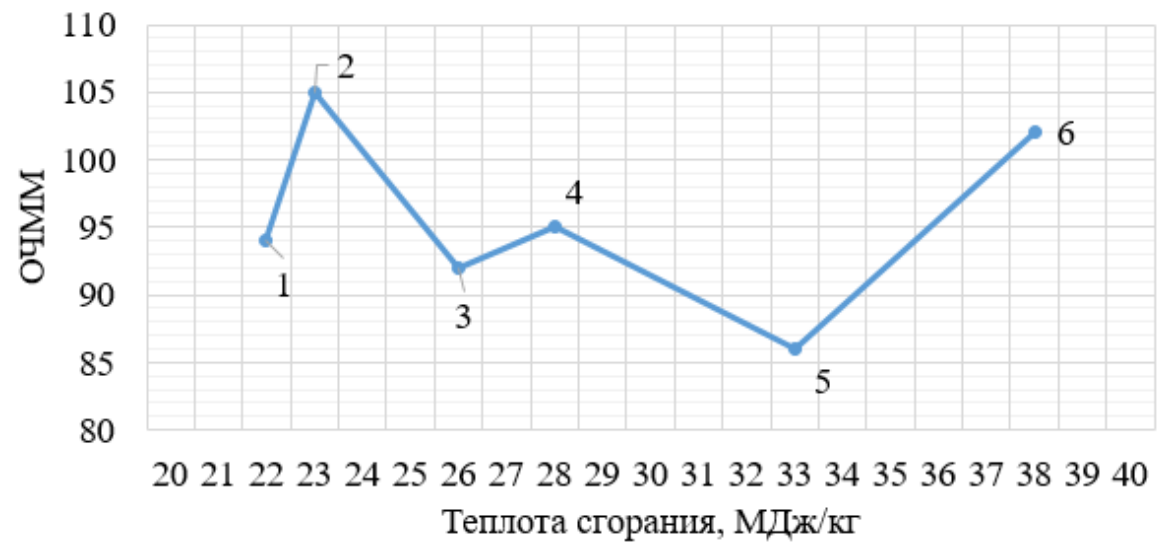

1 - метанол; 2 - этил-трет-бутиловый эфир (ЭТБЭ); 3 - этанол; 4 - трет-бутанол; 5 - изопропиловый спирт; 6 - метил-трет-бутиловый эфир (МТБЭ)

Рисунок 1. Зависимость теплоты сгорания оксигенатов от ОЧММ 
Спирты уже долгое время применяются как самостоятельное топливо, так и в качестве добавок. Метанол обладает высокой детонационной стойкостью и удовлетворительной испаряемостью. Высокая теплота испарения обуславливает пониженную температуру запуска двигателя и его повышенную мощность [2].

Этанол наиболее эффективен как антидетонатор при его добавлении в топливо до 10 \% объемн. На сегодняшний день этиловый спирт в смеси с бензином эффективно применяется как топливо для двигателей внутреннего сгорания (ДВС).

Бутанол по техническим характеристикам превосходит этанол теплота сгорания на $25 \%$ выше, чем у этанола, и на $10 \%$ выше, чем у бензина. Он не опасен в использовании, поскольку в 6 раз меньше испаряется, чем этанол, и в 13,5 раза менее летуч, чем бензин, не вызывает коррозию [3].

Основным оксигенатом в течение 20 лет являлся метил-трет-бутиловый эфир, содействующий сгоранию топлива в полной мере и повышающий октановое число бензина (по исследовательскому методу 115-135 ед.). МТБЭ в бензины добавляют в количестве от $5 \%$ до $15 \%$ [4].

Автобензин, в составе которого присутствует МТБЭ, обладает следующими свойствами:

- повышаются антидетонационные характеристики легкокипящих составляющих бензина (при добавлении к прямогонному бензину с октановым числом по ИМ 55 - 56 пунктов МТБЭ в количестве $5 \%$ объемн., 10 \% объемн. и $15 \%$ объемн. октановые числа изменяются соответственно до 60; 64; 67 пунктов);

- снижается температура запуска двигателя (температура холодного запуска двигателя снижается на $8-15{ }^{\circ} \mathrm{C}$ ) [5];

- увеличивается срок службы деталей двигателя;

- снижается расход топлива. 
Общим преимуществом эфиров и спиртов является меньший выброс токсичных соединений при более полном сгорании, позволяющий снизить выбросы окисей углерода на 32,5 \%, углеводородов - на 14,5 \% и снизить выброс бензола. Оксигенаты обладают меньшей нагарообразующей способностью по сравнению с углеводородами [6].

Улучшить антидетонационные характеристики можно также благодаря смешению товарного топлива с алкилатом [7]. Он удовлетворяет современным экологическим требованиям, ОЧИМ составляет 96 пунктов. Несмотря на преимущества алкилата, в связи с трудоемкостью процесса производства, он является дорогостоящим компонентом, нет возможности в полной мере удовлетворить потребности населения, но для доведения октанового числа смешения до требуемого является лучшим реагентом. Его доля в производимых автомобильных бензинах в США составляет 11,2 \%, в Западной Европе - 5,0 \%, а в России - менее 1,0 \%.

Улучшение антидетонационных свойств бензиновых фракций может быть осуществлено при отправлении их на изомеризацию.

Наличие легких фракций в автобензинах определяет стабильную работу ДВС на стадии пуска, особенно при пониженных температурах в зимних условиях эксплуатации.

Современные автомобильные топлива не должны содержать более 35 \% ароматических углеводородов, в том числе $1 \%$ бензола [8].

В компонентном составе суммарного фонда бензинов РФ содержание риформата достигает $54 \%$, в котором концентрация ароматических углеводородов составляет 56-65 \%, в том числе бензола около 5 \%. Отсюда вытекает задача разработки и внедрения дополнительных процессов переработки риформата с целью снижения содержания в нем бензола. Данная проблема решается посредством изомеризации легких бензиновых фракций [9]. 


\section{Исследовательская часть}

Для экспресс-оценки целесообразно применять методы аналитической химии. К ним относятся ультрафиолетовая спектроскопия, рентгенфлуоресцентная спектроскопия, атомно-адсорбционная спектроскопия, масс-спектрометрия с индуктивно связанной плазмой, ядерный магнитный резонанс и инфракрасная (ИК) спектроскопия.

Ультрафиолетовая спектроскопия на сегодняшний день широко распространена. Но она имеет такие недостатки, как наложение спектров и их неудовлетворяющую избирательность. При применении рентгенфлуоресцентной спектроскопии возможно установить только элементный состав.

При атомно-адсорбционном методе происходит сжигание образца с ацетиленом, что требует проведения анализа во взрывопожаробезопасном помещении. Недостатком спектрометров ядерно-магнитного резонанса является их стоимость, измеряемая десятками миллионов рублей.

Наиболее доступным и информативным является метод поглощения излучения в ИК-спектре с последующим разложением в ряд Фурье. В данном разделе оптической спектроскопии можно получать и анализировать спектры испускания, поглощения и отражения в ИКобласти. Также как и спектры в УФ (ультрафиолетовых) областях, ИКспектры получают и исследуют теми же методами, но приборы отличаются спецификой для исследований в ИК-области, т.е. снабжены зеркальной фокусирующей оптикой и приемниками, восприимчивыми к ИКизлучению. ИК-спектроскопия, в первую очередь, изучает колебательные и вращательные спектры молекул. Также при помощи данных методов исследуются спектры излучения атомов и ионов, образующихся между близкими уровнями энергии в результате их переходов, спектры поглощения и отражения твердых тел, спектры испускания молекул и т.д.

В данной работе для определения содержания добавок (МТБЭ, алкилат, метанол, этанол) применяется метод «Определение МТБЭ, ЭТБЭ, 
метанола, этанола и трет-бутанола методом инфракрасной спектроскопии» по ГОСТ 32338-2013.

В качестве ИК-Фурье применялся аппарат ERASPEC. В ГОСТ 323382013 указано, что в ячейку для жидкой пробы вводят исследуемый образец. Пучок лучей, проходя сквозь пробу, попадает на детектор, где его сигнал регистрируется. Область ИК-спектра подбирается с помощью установки высокоизбирательных полосовых фильтров перед образцом или после него, или аналитическим путем после получения полного спектра. При применении математического расчёта происходит преобразование сигнала детектора для исследуемой области в спектре пробы в содержание каждого компонента в анализируемом образце.

С помощью заранее проанализированных товарных топлив в приборе создается библиотека эталонов, в которую заносятся интересующие лаборанта параметры топлива, и далее прибор использует данную библиотеку для решения обратной задачи, когда характеристики топлива неизвестны, но известен его ИК-спектр.

В качестве объектов исследования взяли бензин коксования, изомеризат, алкилат, риформат, бензин каталитического крекинга и ряд кислородсодержащих соединений (оксигенатов). K характеристикам бензинов относятся плотность, групповой компонентный состав, октановое число, содержание оксигетанов и бензола.

Вышеуказанные характеристики можно определить с помощью газового хроматографа по Детальному углеводородному анализу (ДУА), время анализа на котором составляет около 2,5 ч, без учета времени подготовки прибора. Во время анализа на газовом хроматографе ароматические и непредельные углеводороды часто оказываются неопределенными из-за непостоянства времени выхода. Примерно 20-30\% компонентов в бензинах во время расшифровки оказываются нераспознанными из-за сложного изомерного строения. Далее расчетным способом с применением библиотеки (около 700 компонентов) определяются плотность, фракционный состав, октановое число, 
температура вспышки. Однако данный метод имеет высокую погрешность. Поэтому в данной работе предлагается определять характеристики бензинов с помощью ИК-спектрометрии. Время одного анализа с подготовкой прибора занимает не более 10 мин.

Инфракрасные совмещенные спектры этилбензола, 3-этилтолуола и 4-этилтолуола представлены на рисунке 2.

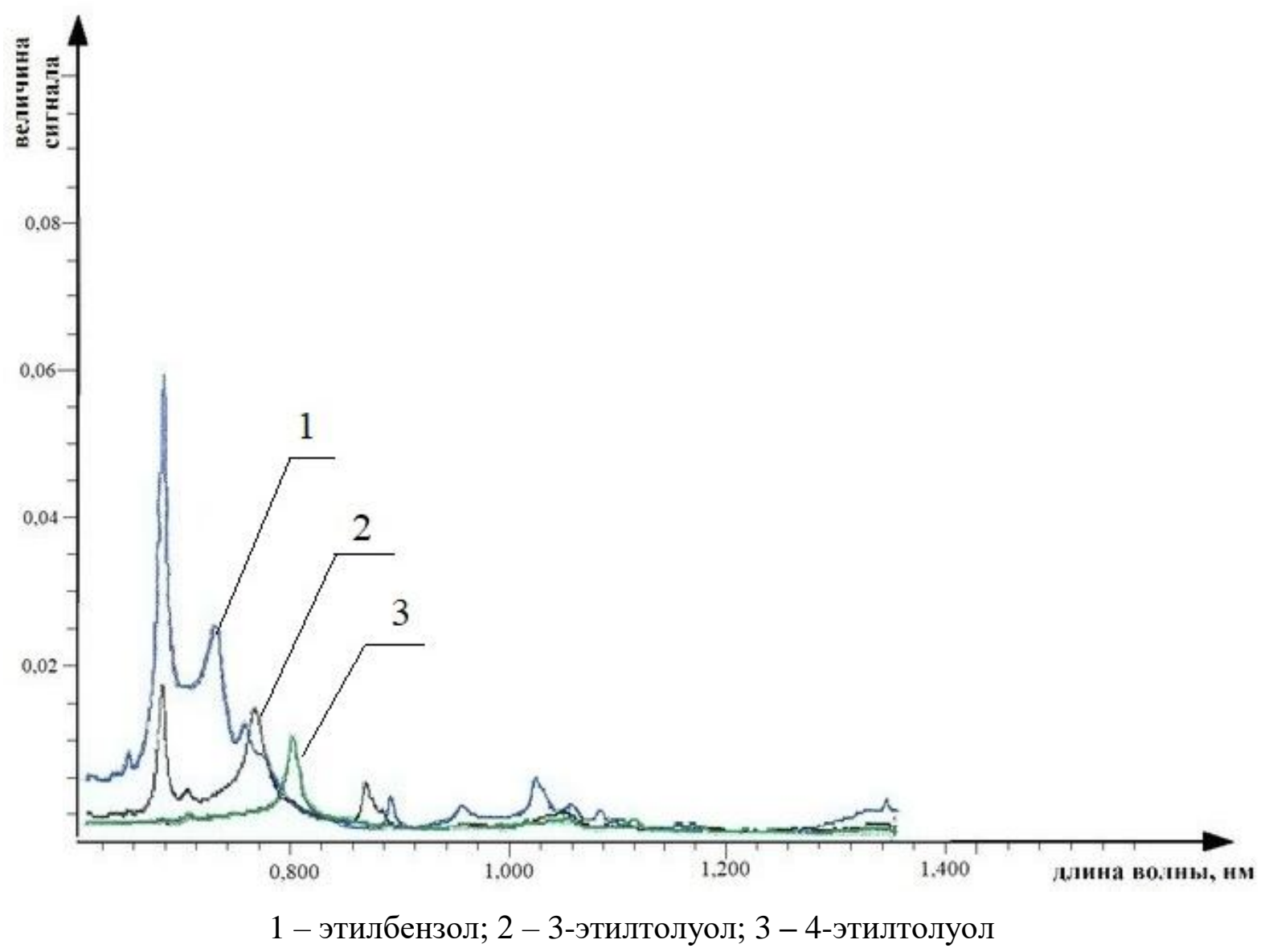

Рисунок 2. Совмещенные спектры этилбензола, 3-этилтолуола и 4-этилтолуола

Совмещенные спектры мецитилена, псевдокумола и нафталина представлены на рисунке 3 , спектры трет-бутанола, МТБЭ и метанола - на рисунке 4. 


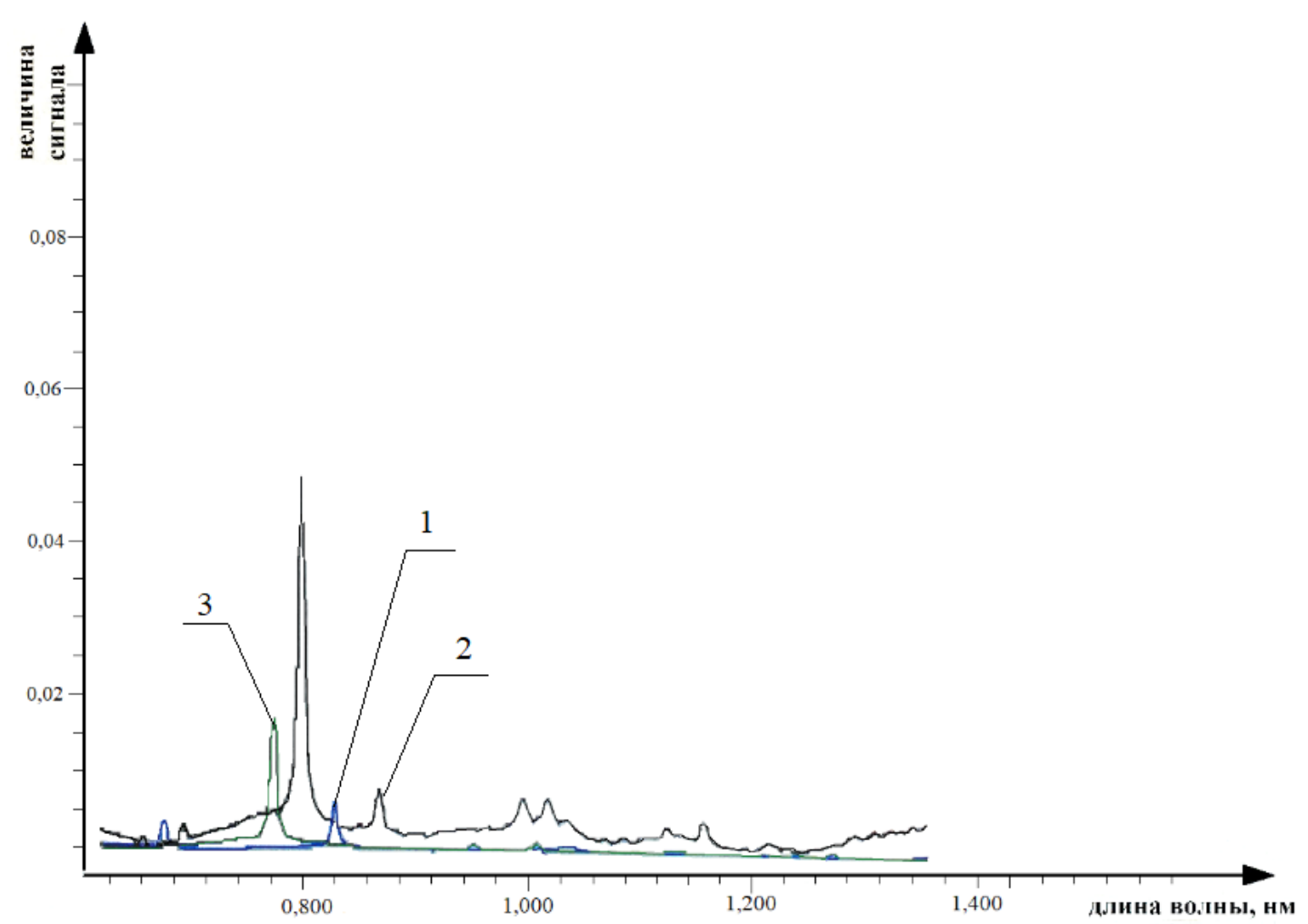

1 - мецитилен; 2 - псевдокумол; 3 - нафталин

Рисунок 3. Совмещенные спектры мецитилена, псевдокумола и нафталина

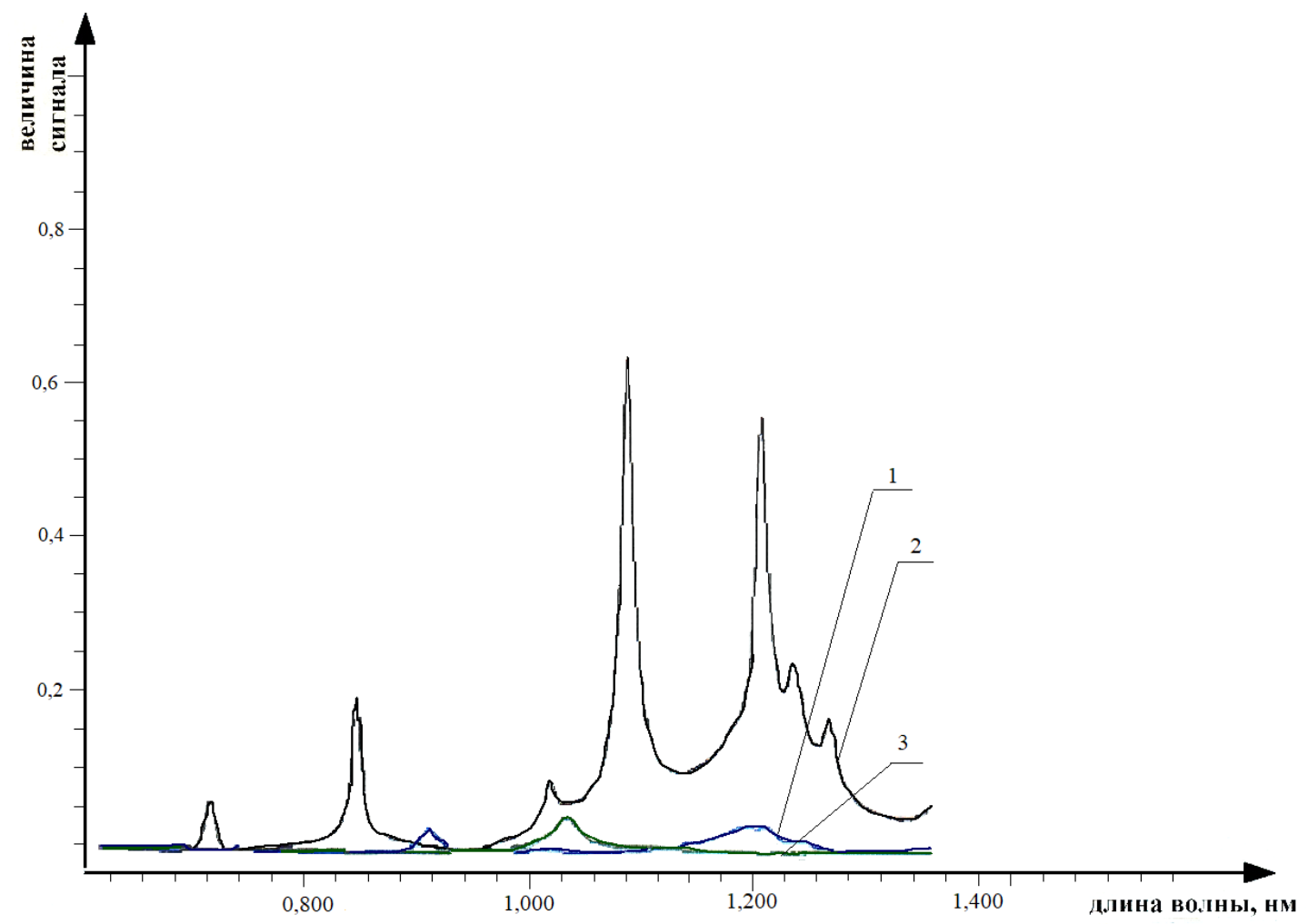

1 - трет-бутанол; 2 - МТБЭ; 3 - метанол

Рисунок 4. Совмещенные спектры трет-бутанола, МТБЭ и метанола 
Интенсивность пиков на рисунках 2-4 больше на длинах волн 500-1300 нм. Данные колебания соответствуют колебаниям СО-, -ОН в оксигенатных группировках [7].

Результаты исследований по определению некоторых характеристик бензинов представлены в таблице 2 .

Таблица 2. Характеристики исследуемых топлив

\begin{tabular}{|l|c|c|c|c|c|}
\hline \multirow{2}{*}{\multicolumn{1}{|c|}{ Определяемое вещество }} & \multicolumn{2}{|c|}{ Содержание компонентов, \% объемн. } & \multicolumn{2}{c|}{ ОЧ } \\
\cline { 2 - 7 } & $\begin{array}{c}\text { ароматические } \\
\text { углеводороды }\end{array}$ & $\begin{array}{c}\text { олефин } \\
\text { ы }\end{array}$ & алканы & ИМ & ММ \\
\hline Бензин коксования & 4,8 & 24,0 & 71,2 & 90,5 & 78,4 \\
\hline Изомеризат & 2,0 & 0 & 98,0 & 86,0 & 81,6 \\
\hline Алкилат & 0 & 0 & 100,0 & 84,8 & 80,9 \\
\hline Риформат & 46,6 & 4,8 & 48,6 & 96,8 & 85,3 \\
\hline Бензин каталитического крекинга & 27,7 & 34,5 & 37,8 & 94,0 & 82,9 \\
\hline
\end{tabular}

Спектрограммы бензина коксования, изомеризата, алкилата, бензина каталитического крекинга, риформата и товарного бензина АИ-95 представлены на рисунках 5-10.

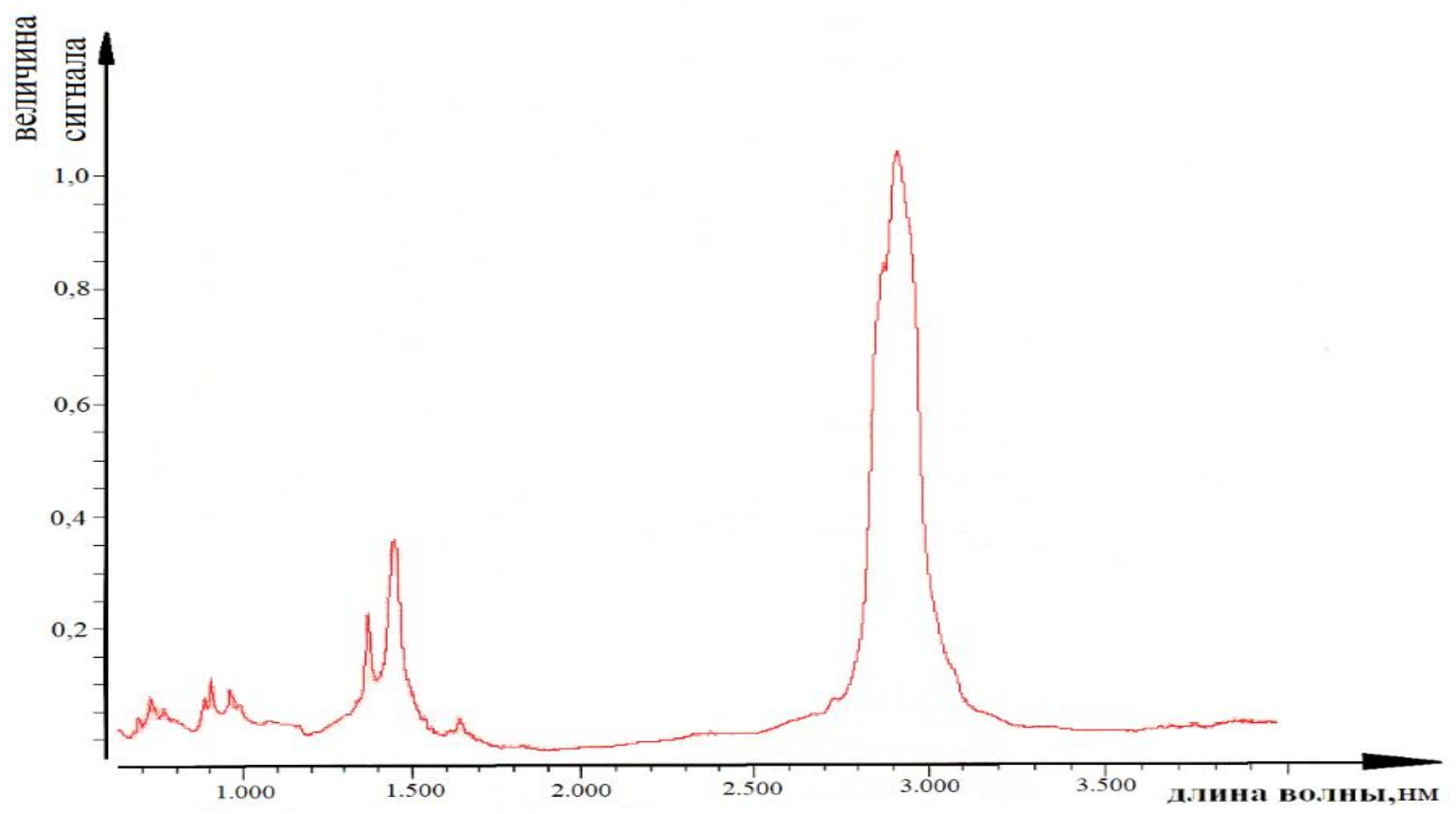

Рисунок 5. Спектрограмма бензина коксования 


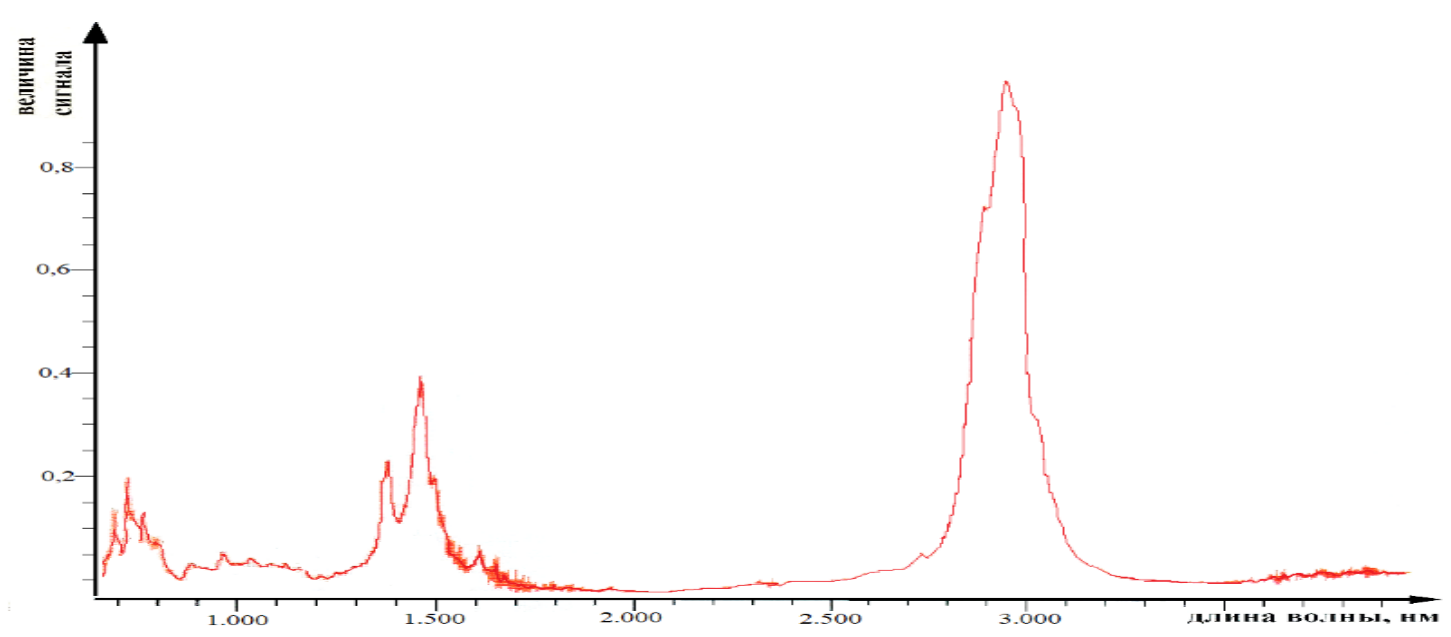

Рисунок 6. Спектрограмма изомеризата

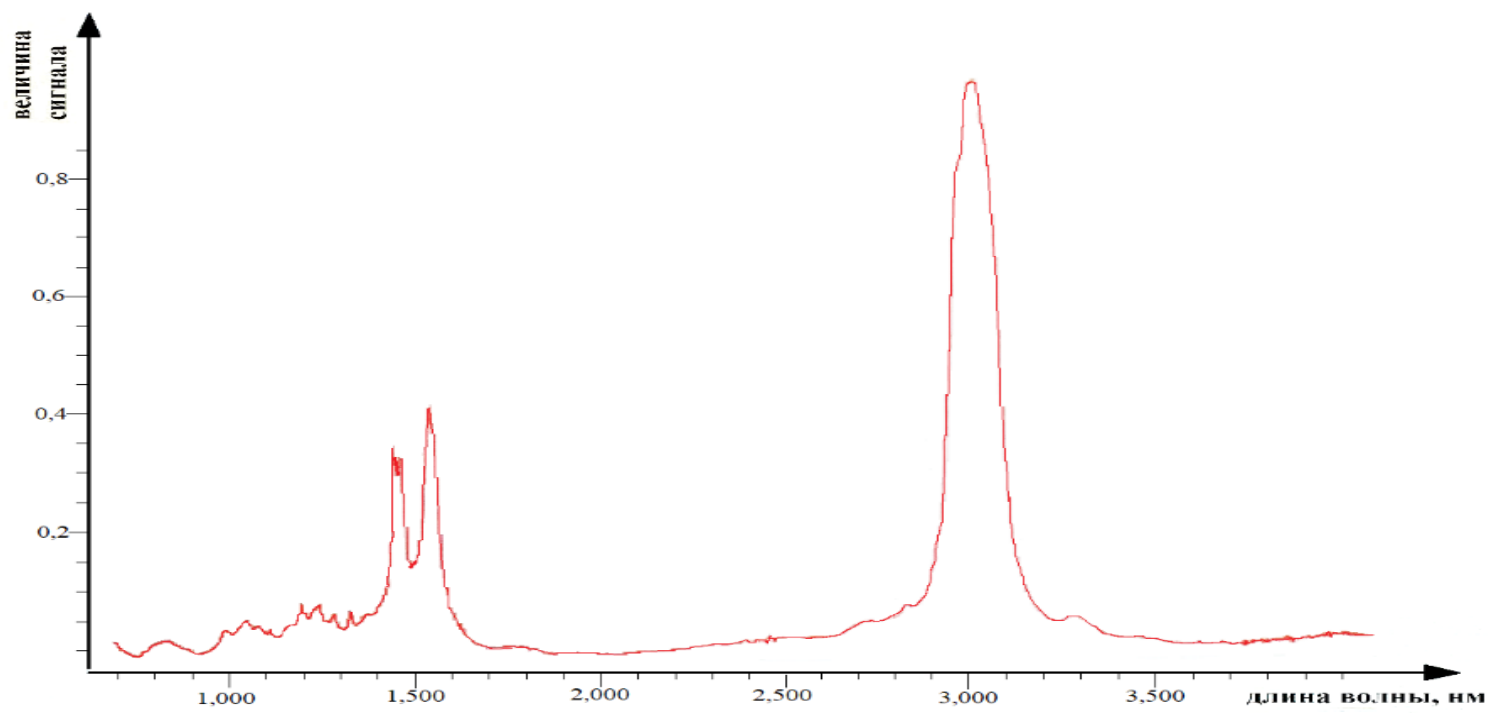

Рисунок 7. Спектрограмма алкилата

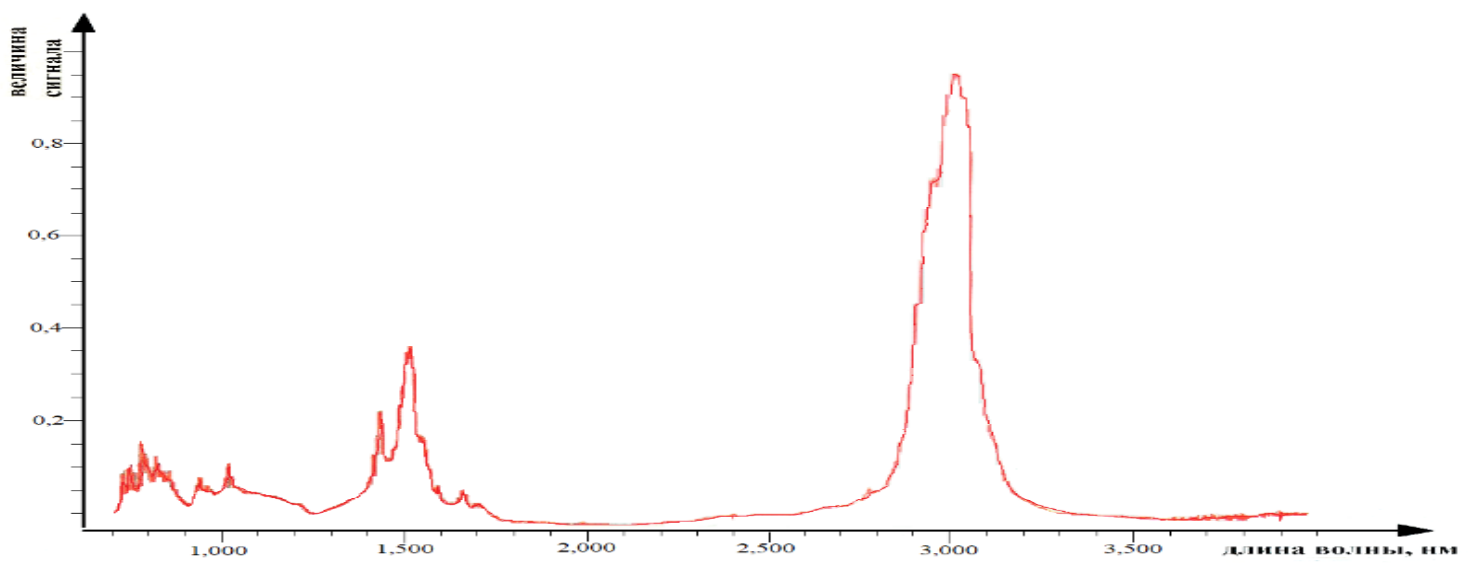

Рисунок 8. Спектрограмма бензина каталитического крекинга 


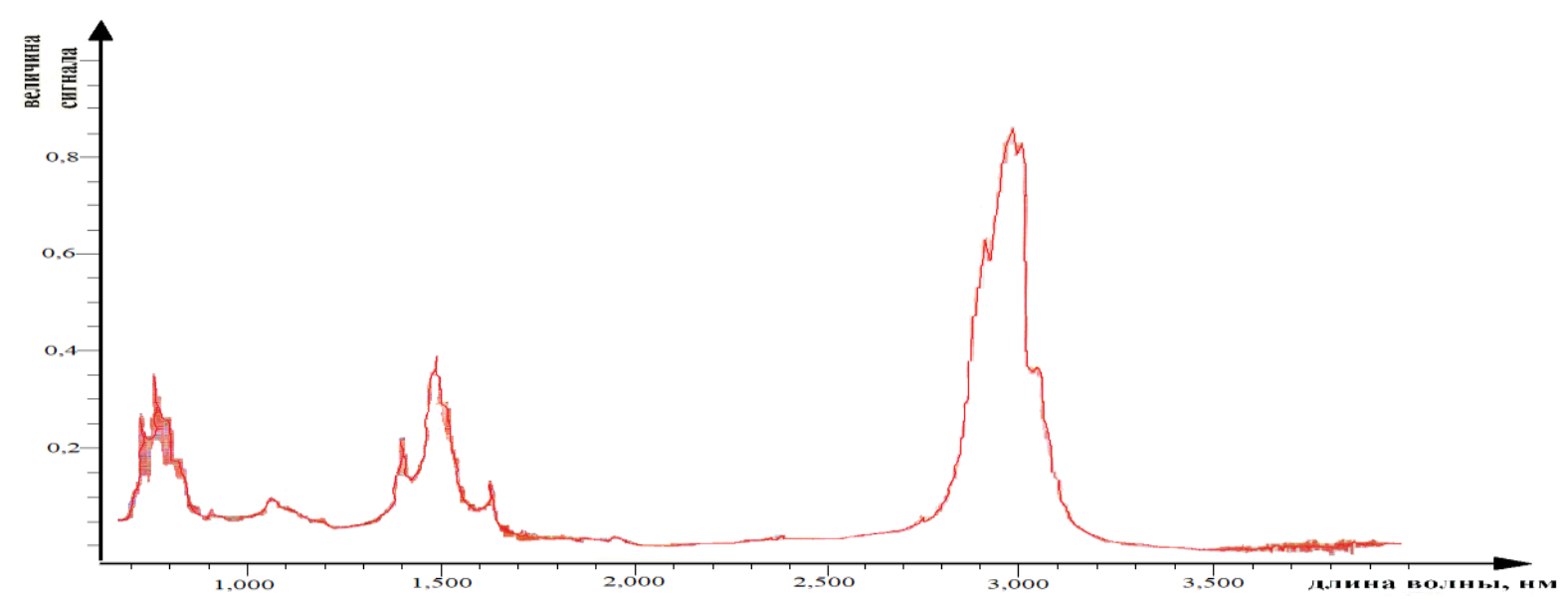

Рисунок 9. Спектрограмма риформата

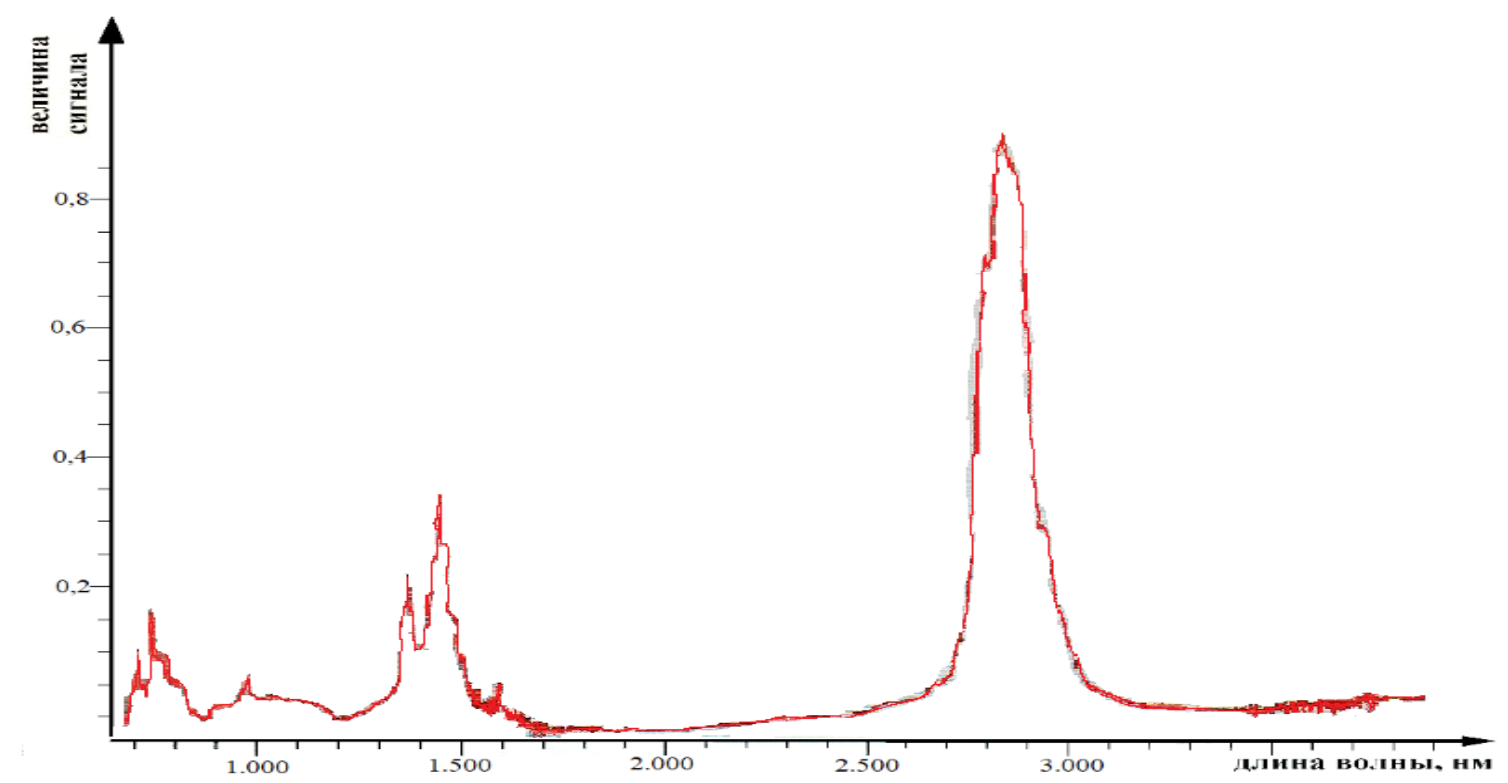

Рисунок 10. Спектрограмма товарного бензина АИ-95

На рисунках 5-10 на длинах волн 1000-2000, 2500-3500 нм наблюдаются различия в интенсивности пиков, что говорит о содержащихся связях $-\mathrm{CH}^{-}, \mathrm{CH}_{2}^{-}, \mathrm{CH}_{3}^{-}[10]$.

В товарном бензине АИ-95 наблюдается интенсивность пиков на длинах волн 700-1100 и 1200-1700 нм. Данные колебания соответствуют колебаниям $\mathrm{C}=\mathrm{O}$ и $\mathrm{O}-\mathrm{H}$ в оксигенатных группировках, которые, согласно паспорту, присутствуют в данном виде бензина. К ним относятся третбутанол и метил-трет-бутиловый эфир. Интенсивность пиков на длинах волн 2500-3200 нм совпадает с аналогичными пиками риформата, бензина 
каталитического крекинга, изомеризата и алкилата (рисунки 6-9), что свидетельствует об их возможном содержании в исследуемом топливе.

\section{Вывод}

Экспериментально получены совмещенные спектры компонентов автомобильного топлива. С помощью метода ИК-Фурье спектроскопии определены качественный состав и основные компоненты бензина АИ-95, а именно содержание оксигенатов, алкилата, риформата, изомеризата и бензина каталитического крекинга. Установлено, что данный метод экспрессный, дешевый и доступный для оценки качества бензинов. Полученные результаты свидетельствуют о возможности применения ИК-спектроскопии в качественном анализе состава топливных смесей.

\section{Список используемых источников}

1. Шараф А.М. Антидетонационные добавки на основе синергетических смесей оксигенатов к бензиновым топливам: дис. ... д-ра техн. наук. Казань: Изд-во КНИТУ, 2018. 114 с.

2. Гуреев А.А., Азев В.С. Автомобильные бензины. Свойства и применение. М.: Нефть и газ, 1996. 444 с.

3. Опарина Л.А., Колыванов Н.А., Гусарова Н.К., Сапрыгина В.Н. Оксигенатные добавки к топливу на основе возобновляемого сырья // Известия вузов. Прикладная химия и биотехнология. 2018. № 1. С. 19-34. DOI: $10.21285 / 2227-2925-2018-8-1$-19-34.

4. Weinberg M., Schulte-Korne E., Peters U., Nierlich F. Methyl-TertButyl Ether // Ulmann's Enceclopedia of Industrial Chemistry. Weinheim: Viley-VCH, 2010, 12 p.

5. Карпов С.А. Особенности применения оксигенатов в автомобильном топливе: дис. ... д-ра техн. наук. Уфа: Изд-во УГНТУ, 2012. $450 \mathrm{c}$. 
6. Егоров В.Н., Василевкин Е.В., Пеленский А.В. Применение оксигенатов в моторных топливах для ДВС с искровым зажиганием // Известия МГТУ «МАМИ». 2013. № 1. С. 78-82.

7. Спиркин В.Г. Изомеризат // Энциклопедия. URL: http://knowledge.su/i/izomerizat (дата обращения: 21.04.2019).

8. Абдульминев К.Г., Ахметов А.Ф., Федоринов И.А. Исследование технологии получения низкоароматизированных высокооктановых компонентов автомобильных топлив // Башкирский химический журнал. 2003. № 3. C. 60-63.

9. Мириманян А.А., Вихман А.Г., Мкртычев А.Л. Промышленный опыт работы установок изомеризации пентан-гексановой фракции // Нефтепереработка и нефтехимия. 2006. № 4. С. 22-31.

10. Вяземский А.Д. ИК-спектры поглощения органических соединений // Инфракрасная спектроскопия. URL: http://him.1sept.ru/ article.php?ID=200202101 (дата обращения: 09.06.2019).

\section{References}

1. Sharaf A.M. Antidetonatsionnye dobavki na osnove sinergeticheskikh smesei oksigenatov k benzinovym toplivam: dis. d-ra tekhn. Nauk [Anti-Knock Additives Based on Synergistic Mixtures of Oxygenates to Gasoline Fuels: Cand. Engin. Sci. Diss.]. Kazan, Izd-vo KNITU Publ., 2018. 114 p. [in Russian].

2. Gureev A.A., Azev V.S. Avtomobil'nye benziny. Svoistva i primenenie [Motor Gasoline. Properties and Applications]. Moscow, Neft' i gaz Publ., 1996. 444 p. [in Russian].

3. Oparina L.A., Kolyvanov N.A., Gusarova N.K., Saprygina V.N. Oksigenatnye dobavki $\mathrm{k}$ toplivu na osnove vozobnovlyaemogo syr'ya [Oxygenate Fuel Additives on the Basis of Renewable Raw Materials]. Izvestiya vuzov. Prikladnaya khimiya i biotekhnologiya - Proceedings of Universities. Applied Chemistry and Biotechnology, 2018, No. 1, pp. 19-34. DOI: 10.21285/2227-2925-2018-8-1 -19-34 [in Russian]. 
4. Weinberg M., Schulte-Korne E., Peters U., Nierlich F. Methyl-TertButyl Ether. Ulmann's Enceclopedia of Industrial Chemistry. Weinheim, Viley$\mathrm{VCH}, 2010,12 \mathrm{p}$.

5. Karpov S.A. Osobennosti primeneniya oksigenatov $v$ avtomobil'nom toplive: dis. d-ra tekhn. nauk [Features of Application of Oxygenates in Automobile Fuel: Cand. Engin. Sci. Dis.]. Ufa, Izd-vo UGNTU Publ., 2012. 450 p. [in Russian].

6. Egorov V.N., Vasilevkin E.V., Pelenskii A.V. Primenenie oksigenatov v motornykh toplivakh dlya DVS $\mathrm{s}$ iskrovym zazhiganiem [The Use of Oxygenates in Motor Fuels for Internal Combustion Engines with Spark Ignition]. Izvestiya MGTU «MAMI» - Izvestiya MGTU «MAMI», 2013, No. 1, pp. 78-82. [in Russian].

7. Spirkin V.G. Izomerizat [Isomerizate]. Entsiklopediya. Available at: http://knowledge.su/i/izomerizat (accessed 21.04.2019). [in Russian].

8. Abdul'minev K.G., Akhmetov A.F., Fedorinov I.A. Issledovanie tekhnologii polucheniya nizkoaromatizirovannykh vysokooktanovykh komponentov avtomobil'nykh topliv [Research of Technology of Production of Low-Aromatized High-Octane Components of Automobile Fuels]. Bashkirskii khimicheskii zhurnal - Bashkir Chemical Journal, 2003, No. 3, pp. 60-63. [in Russian].

9. Mirimanyan A.A., Vikhman A.G., Mkrtychev A.L. Promyshlennyi opyt raboty ustanovok izomerizatsii pentan-geksanovoi fraktsii [Industrial-Scale Experience in Running Pentane-Hexane Cut Isomerisation Units]. Neftepererabotka i neftekhimiya - Oil Processing and Petrochemistry, 2006, No. 4, pp. 22-31. [in Russian].

10. Vyazemskii A.D. IK-spektry pogloshcheniya organicheskikh soedinenii [IR Absorption Spectra of Organic Compounds]. Infrakrasnaya spektroskopiya. Available at: http://him.1sept.ru/article.php?ID=200202101 (accessed 09.06.2019). [in Russian]. 


\section{Сведения об авторах}

\section{About the authors}

Гильмутдинов Амир Тимерьянович, доктор технических наук, профессор кафедры «Технология нефти и газа», УГНТУ, г. Уфа, Российская Федерация

Amir T. Gilmutdinov, Doctor of Engineering Sciences, Professor of Oil and Gas Processing Department, USPTU, Ufa, Russian Federation

e-mail: ammir59@mail.ru

Лапшин Игорь Геннадиевич, аспирант кафедры «Технология нефти и газа», УГНТУ, г. Уфа, Российская Федерация

Igor G. Lapshin, Post-graduate Student of Oil and Gas Processing Department, USPTU, Ufa, Russian Federation

e-mail: klods2010@yandex.ru

Тафтиева Ирина Раисовна, студент кафедры «Технология нефти и газа», УГНТУ, г. Уфа, Российская Федерация

Irina R. Taftiyeva, Student of Oil and Gas Processing Department, USPTU, Ufa, Russian Federation

e-mail: taftieva06@mail.ru

Шавалиева Эльвира Рашидовна, студент кафедры «Технология нефти и газа», УГНТУ, г. Уфа, Российская Федерация

Elvira R. Shavalieva, Student of Oil and Gas Processing Department, USPTU, Ufa, Russian Federation

e-mail: elvira.shavalieva.97@mail.ru 